Supporting information for

\title{
Few-layer siloxene as electrode for superior high-rate zinc ion
}

\section{hybrid capacitors}

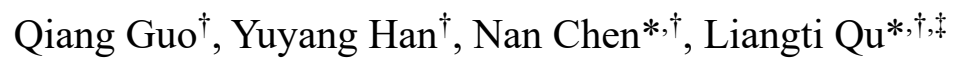

$\dagger$ Key Laboratory of Photoelectronic/Electrophotonic Conversion Materials, Key Laboratory of Cluster Science, Ministry of Education of China, School of Chemistry and Chemical Engineering, Beijing Institute of Technology, Beijing 100081, China $\ddagger$ Key Laboratory of Organic Optoelectronics \& Molecular Engineering, Ministry of Education, Department of Chemistry, Tsinghua University, Beijing 100084, China

E-mail: gabechain@bit.edu.cn; lqu@mail.tsinghua.edu.cn.

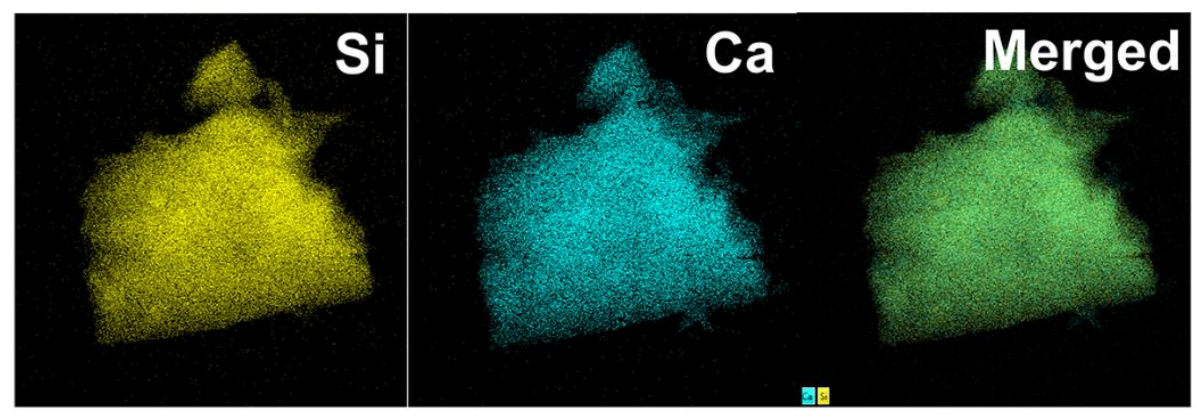

Figure S1. The element mapping of $\mathrm{CaSi}_{2}$.

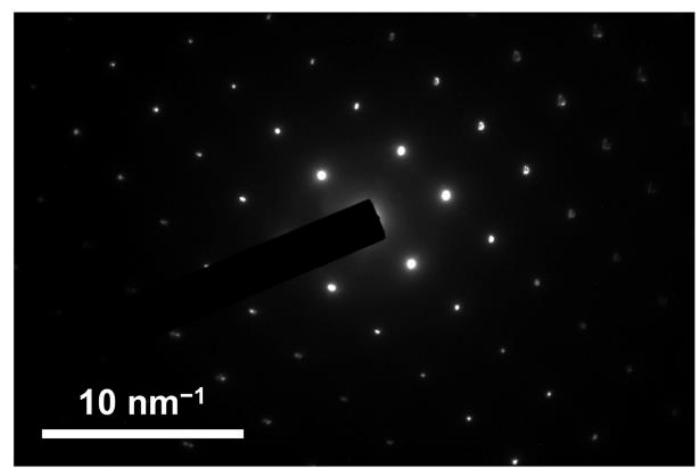

Figure S2. The SAED pattern of $\mathrm{CaSi}_{2}$. 


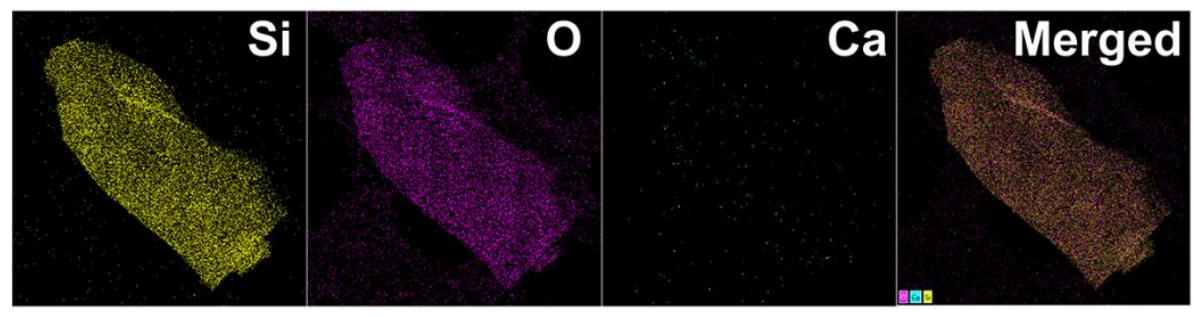

Figure S3. The element mapping of the siloxene nanosheet.

(a)

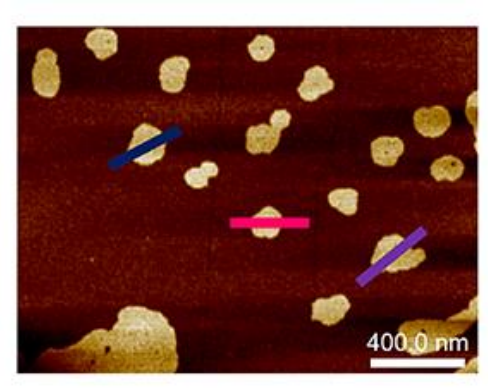

(b)

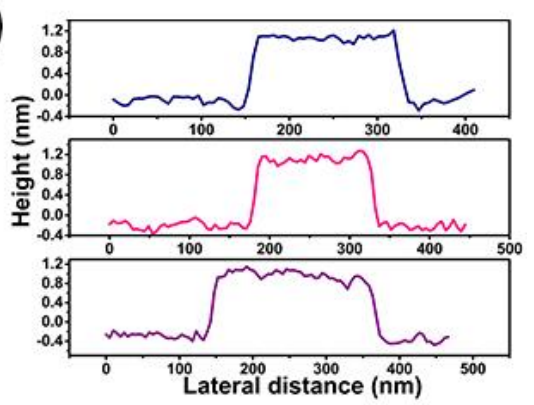

Figure S4. (a) AFM image of siloxene nanosheets. (b) Thickness curves of siloxene nanosheets.

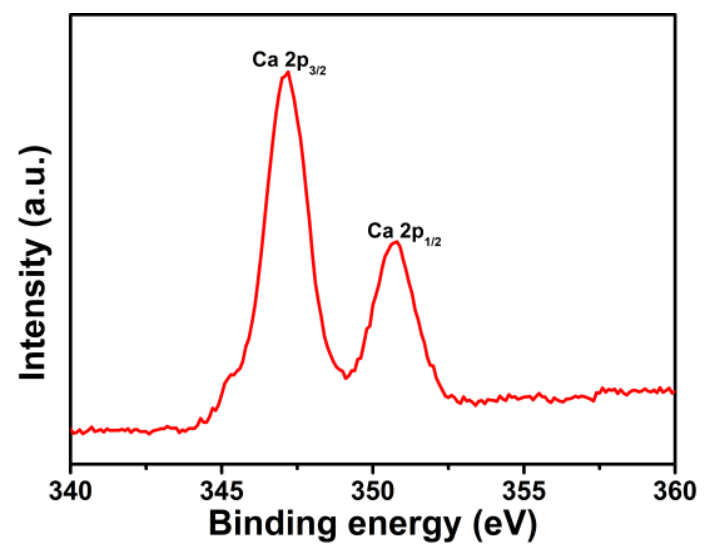

Figure S5. Ca $2 p$ core-level spectra of $\mathrm{CaSi}_{2}$. 


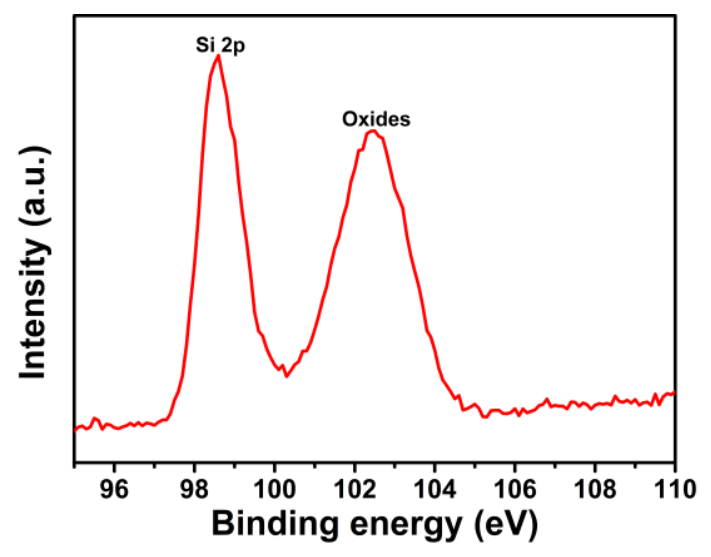

Figure S6. Si 2p core-level spectra of $\mathrm{CaSi}_{2}$.

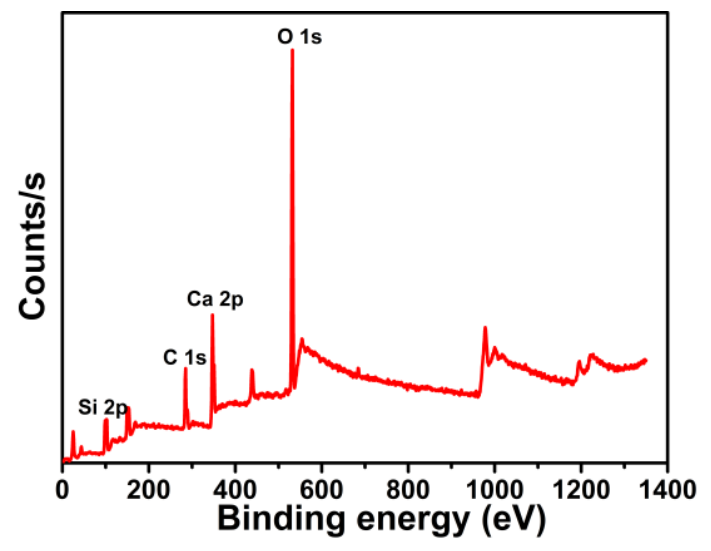

Figure S7. XPS spectrum of $\mathrm{CaSi}_{2}$.

(a)

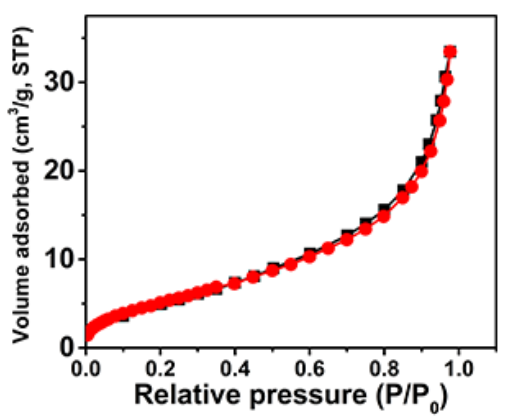

(b)

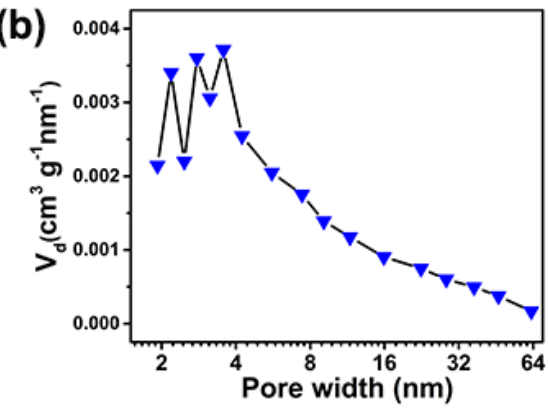

Figure S8. (a) Nitrogen sorption isotherms and (b) pore size distribution of siloxene. 


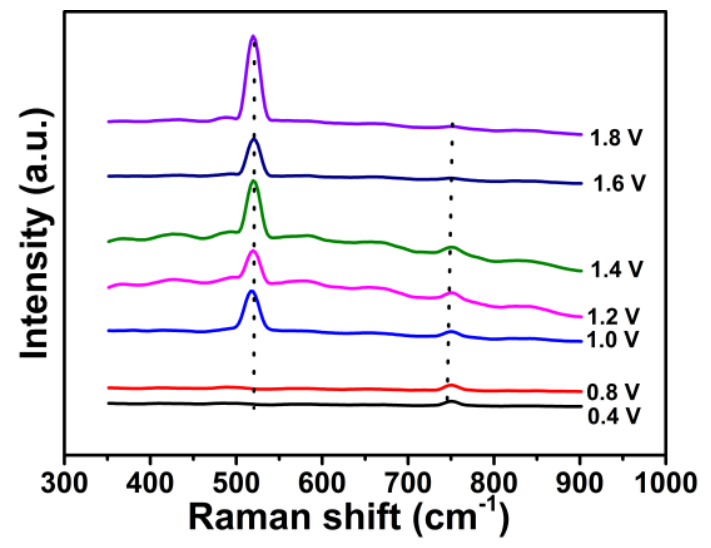

Figure S9. In situ Raman spectra of the siloxene electrode during the charging process.

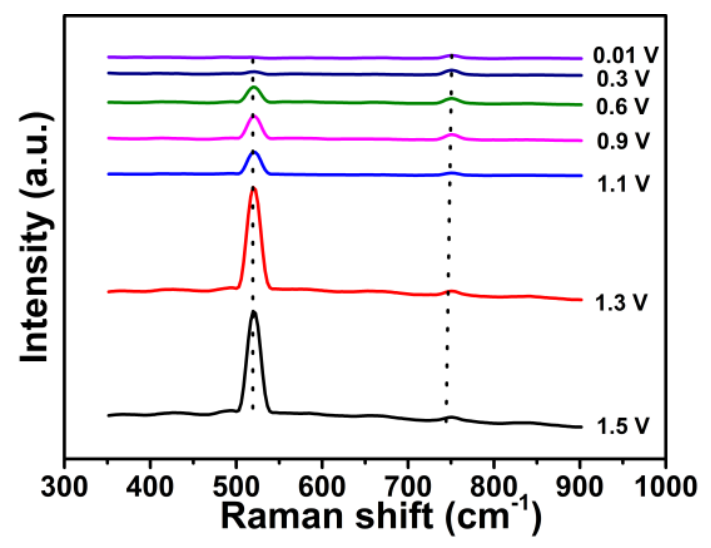

Figure S10. In situ Raman spectra of the siloxene electrode during the discharging process.

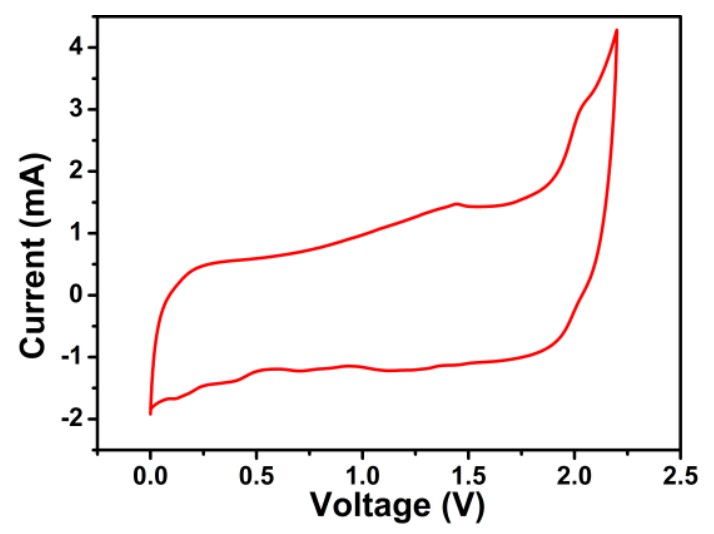

Figure S11. The CV curve of the siloxene ZHC at working voltage between 0 and $2.2 \mathrm{~V}$. 


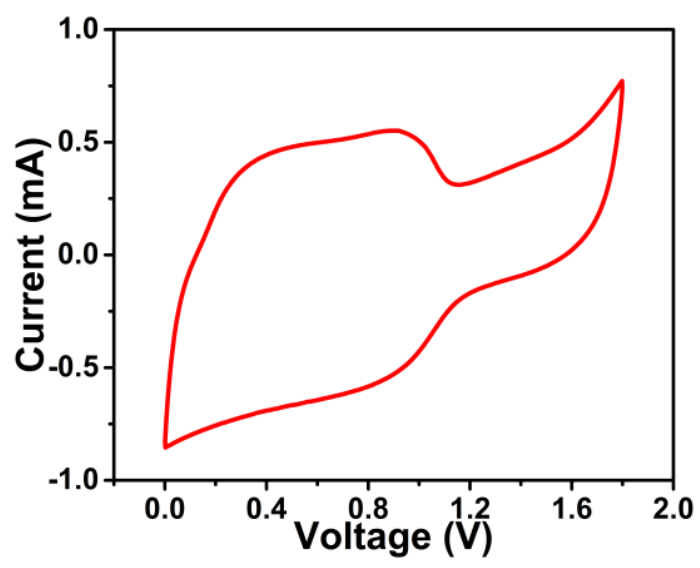

Figure S12. The CV curve of the siloxene ZHC employing pure $21 \mathrm{M}$ LiTFSI as electrolyte at a scan rate of $100 \mathrm{mV} / \mathrm{s}$.

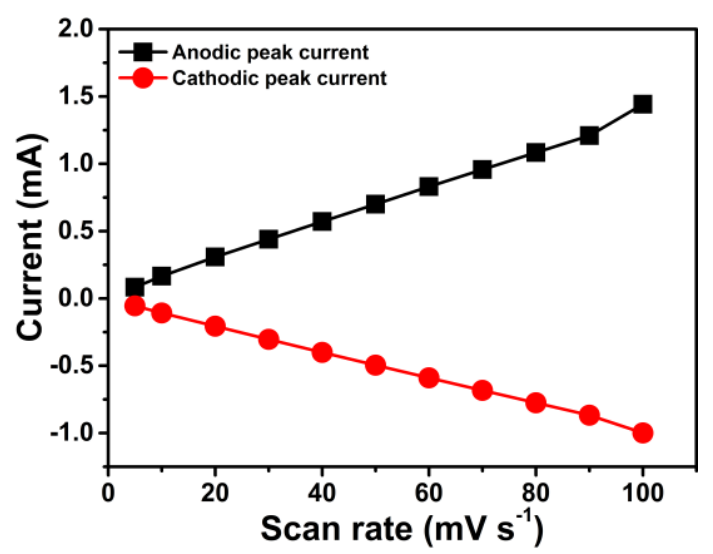

Figure S13. The dependence of peak current on the scan rate.

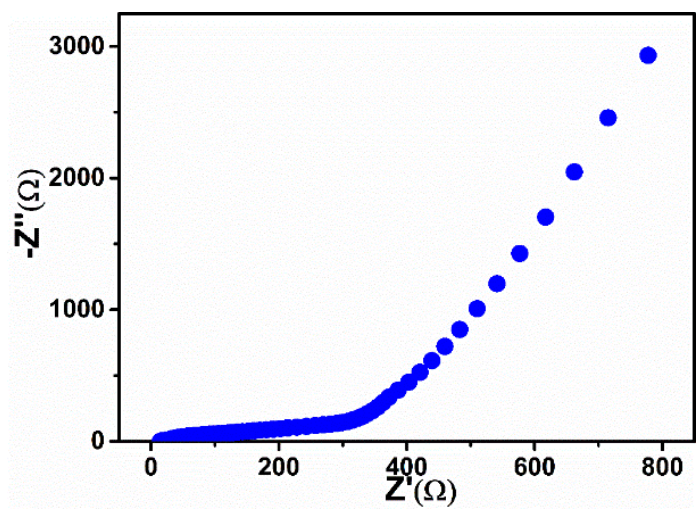

Figure S14. Electrochemical impedance spectroscopy of the siloxene ZHC after cycling. 


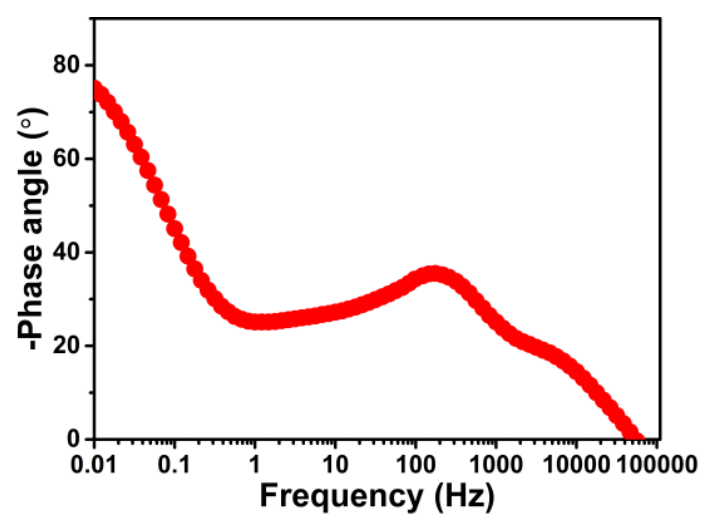

Figure S15. The variation of phase angle with frequency in the siloxene ZHC after cycling.

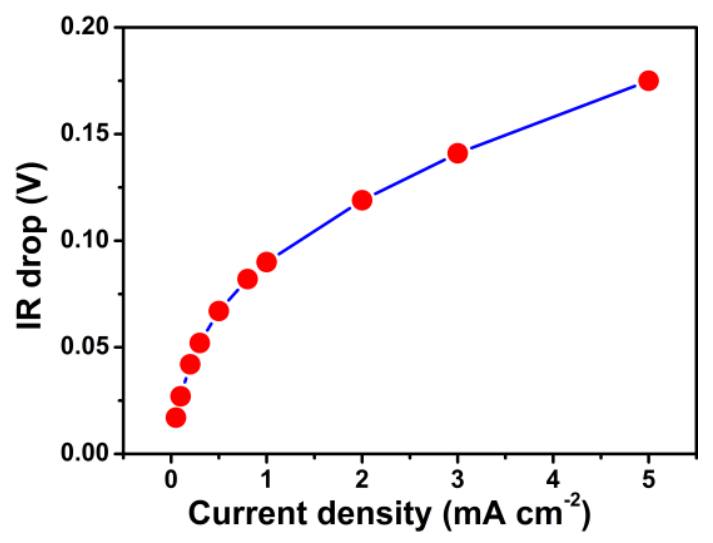

Figure S16. The IR drop of the siloxene ZHC.

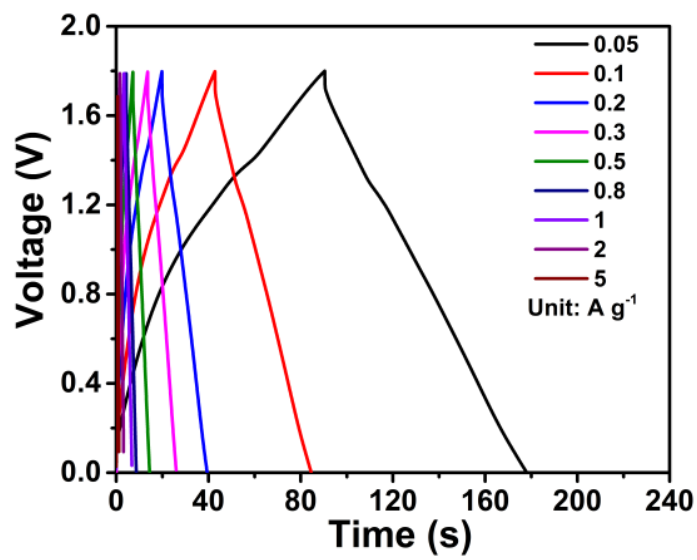

Figure S17. GCD curves of the siloxene ZHC. 


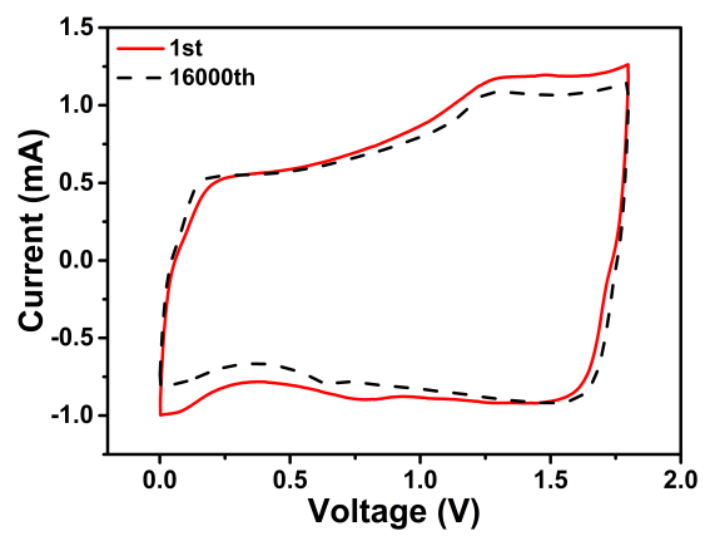

Figure S18. The CV curves of the siloxene ZHC.

Table S1. Performance of the siloxene ZHC in comparison with reported silicon-based electrodes.

\begin{tabular}{|c|c|c|c|c|c|c|}
\hline $\begin{array}{c}\text { Electrode } \\
\text { material }\end{array}$ & Electrolyte & $\begin{array}{l}\text { Potential } \\
\text { window } \\
(\mathrm{V})\end{array}$ & $\begin{array}{c}\text { Specific } \\
\text { capacitance } \\
\left(\mu \mathrm{F} \mathrm{cm}^{-2}\right)\end{array}$ & $\begin{array}{l}\text { Energy } \\
\text { density } \\
\left(\mu \mathrm{J} \mathrm{cm}^{-2}\right)\end{array}$ & $\begin{array}{c}\text { Power } \\
\text { density } \\
\left(\mu \mathrm{W} \mathrm{cm}^{-2}\right)\end{array}$ & Ref. \\
\hline Siloxene & $\mathrm{TEABF}_{4}$ & 0 to 3.0 & 2180 & 3220 & 4030 & {$[1]$} \\
\hline Silicon Nanowire & $\mathrm{PYR}_{13} \mathrm{TFSI}$ & 0 to 4 & 30 & 190 & 1000 to 2000 & {$[2]$} \\
\hline $\begin{array}{c}\text { Silicon } \\
\text { Nanotrees }\end{array}$ & EMI-TFSI & -2.5 to 1.5 & 3800 & 2800 & 2000 & {$[3]$} \\
\hline $\begin{array}{l}\text { Diamond coated } \\
\qquad \mathrm{Si} \mathrm{NWs}\end{array}$ & PMPyrrTFSI & -2.5 to 1.5 & 105 & 84 & 940 & {$[4]$} \\
\hline O-Si NWs & EMI-TFSI & 0 to 4 & 31 & 212 & 472 & {$[5]$} \\
\hline $\begin{array}{c}\text { SiC NWs on } \mathrm{SiC} \\
\text { film }\end{array}$ & $\mathrm{KCl}$ & -0.2 to 0.6 & 240 & 68 & 4 & {$[6]$} \\
\hline $\begin{array}{c}\mathrm{SiC} \text { coated } \mathrm{Si} \\
\mathrm{NWs}\end{array}$ & $\mathrm{KCl}$ & -0.2 to 0.6 & 1700 & 850 & 100 & [7] \\
\hline $\mathrm{SiC} \mathrm{NW}$ & $\mathrm{KCl}$ & 0.0 to 0.6 & 23000 & 2300 & 1100 & {$[8]$} \\
\hline p-SiNWs & $\mathrm{NEt}_{4} \mathrm{BF}_{4}$ & -1.3 to -0.5 & 46 & 3 & 1600 & [9] \\
\hline Porous Si & PEO-EMIBF 4 & 0 to 0.65 & 3500 & 612 & 22 & [10] \\
\hline Siloxene & $\begin{array}{c}21 \mathrm{M} \mathrm{LiTFSI} \\
\text { and } 1 \mathrm{M} \\
\mathrm{Zn}\left(\mathrm{CF}_{3} \mathrm{SO}_{3}\right)_{2}\end{array}$ & 0 to 1.8 & 6860 & 10660 & 4500 & $\begin{array}{l}\text { This } \\
\text { work }\end{array}$ \\
\hline
\end{tabular}




\section{References:}

1. Krishnamoorthy, K.; Pazhamalai, P.; Kim, S.-J. Two-dimensional siloxene nanosheets: novel high-performance supercapacitor electrode materials. Energy Environ. Sci. 2018, 11, 1595.

2. Aradilla, D.; Gentile, P.; Bidan, G.; Ruiz, V.; Gómez-Romero, P.; Schubert, T.J.S.; Sahin, H.; Frackowiak, E.; Sadki, S. High performance of symmetric microsupercapacitors based on silicon nanowires using N-methyl-Npropylpyrrolidinium bis(trifluoromethylsulfonyl)imide as electrolyte. Nano Energy 2014, 9, 273.

3. Gaboriau, D.; Aradilla, D.; Brachet, M.; Le Bideau, J.; Brousse, T.; Bidan, G.; Gentile, P.; Sadki, S. Silicon nanowires and nanotrees: elaboration and optimization of new 3D architectures for high performance on-chip supercapacitors. $R S C A d v$. 2016, 6, 81017.

4. Gao, F.; Lewes-Malandrakis, G.; Wolfer, M. T.; Müller-Sebert, W.; Gentile, P.; Aradilla, D.; Schubert, T.; Nebel, C. E. Diam. Diamond-coated silicon wires for supercapacitor applications in ionic liquids. Relat. Mater. 2015, 51, 1.

5. Berton, N.; Brachet, M.; Thissandier, F.; Le Bideau, J.; Gentile, P.; Bidan, G.; Brousse, T.; Sadki, S. Wide-voltage-window silicon nanowire electrodes for micro-supercapacitors via electrochemical surface oxidation in ionic liquid electrolyte. Electrochem. commun. 2014, 41, 31.

6. Alper, J. P.; Kim, M. S.; Vincent, M.; Hsia, B.; Radmilovic, V.; Carraro, C.; Maboudian, R. Silicon carbide nanowires as highly robust electrodes for microsupercapacitors. J. Power Sources 2013, 230, 298.

7. Alper, J. P.; Vincent, M.; Carraro, C.; Maboudian, R. Silicon carbide coated silicon nanowires as robust electrode material for aqueous micro-supercapacitor. Appl. Phys. Lett. 2012, 100, 163901.

8. Gu, L.; Wang, Y.; Fang, Y.; Lu, R.; Sha, J. Performance characteristics of supercapacitor electrodes made of silicon carbide nanowires grown on carbon fabric. J. Power Sources 2013, 243, 648.

9. Thissandier, F.; Le Comte, A.; Crosnier, O.; Gentile, P.; Bidan, G.; Hadji, E.; Brousse, T.; Sadki, S. Highly doped silicon nanowires based electrodes for microelectrochemical capacitor applications. Electrochem. Commun. 2012, 25, 109.

10. Cohn, A. P.; Erwin, W. R.; Share, K.; Oakes, L.; Westover, A. S.; Carter, R. E.; Bardhan, R.; Pint, C. L. All silicon electrode photocapacitor for integrated energy storage and conversion. Nano Lett., 2015, 15, 2727. 